\title{
realización y gastos de la construcción en invierno
}

Prof. Dr. Ing. WOLFGANG TRIEBEL, Hannover

La construcción en tiempo frío se encuentra dificultada por motivos tanto sociales como técnicos y económicos. Por estas razones no se ha construido o se ha hecho en pequeña escala durante el invierno, en tanto que las ventajas obtenidas no se puedan justificar, o bien que, por razones imprescindibles, haya que cargar con los gastos correspondientes.

Una situación de este tipo surgió precisamente hace unos años en Alemania Occidental. La creciente necesidad de viviendas y el interés, por otra parte, en reducir algo la escasez en el mercado de la construcción, obliga a aumentar el rendimiento en la economía de la construcción. Esto se puede realizar sin nuevas inversiones, manteniendo una actividad durante todo el año, y aprovechando plenamente la maquinaria y aparatos disponibles. Con esta actividad continua se crea una base importante para la racionalización en la construcción. Para conseguir esto es necesaria la construcción durante el invierno, a pesar de todas las cargas que se originan al aprovechar todos los medios técnicos auxiliares necesarios para la obra.

La construcción en invierno motiva gastos adicionales si se tratan de evitar las desventajas que van ligadas a los trabajos en esta época del año. La cuantía de estos gastos, depende del tipo, y amplitud de la obra, del tipo y amplitud de trabajo, del equipo disponible, de la inclemencia del invierno y de la duración de los trabajos.

Tratándose de edificios altos o edificios para viviendas, hay que distinguir entre los trabajos de la estructura y cerramiento y los trabajos interiores. En relación con los primeros, que representan la parte más penosa, hay que distinguir los siguientes tipos:

a) Obra abierta a la intemperie.

b) Obra cubierta en parte.

c) Obra cubierta o completamente cerrada.

\section{Tabajos interiores en invierno}

El caso más fácil es realizar trabajos cuando el edificio se ha terminado en su obra de cerramiento antes de llegar el invierno; esto es lo que se viene haciendo desde hace muchos años. Lo primero de esta tarea interior es cerrar huecos colocando ventanas y puertas; si esto no se hace, se cierra provisionalmente sobre los marcos con hojas de material plástico (figura 1). En determinadas condiciones, será ventajoso secar artificialmente la obra antes de comenzar los trabajos interiores. 
Los gastos adicionales para estos trabajos previos y la calefacción, en el tiempo que duran los trabajos interiores, resultan ser del 1 al 1,8 por 100 del gasto total de obra si se considera una casa de tipo medio. Esto puede suponer, según el tamaño de la vivienda y el tiempo de calefacción, de 250 a $400 \mathrm{DM} /$ vivienda. La mitad de esto corresponde a la calefacción y a la conservación de las estufas. Este gasto se reduce cuando se ha colocado previamente la calefacción central, la cual puede ponerse en marcha ya durante la realización de los trabajos interiores.

Realizando sólo trabajos interiores durante el invierno, no se resuelve realmente el problema de la construcción en esta época del año. Si en todos los edificios se hiciese esto, se limitaría la ocupación de los operarios de estas especialidades; por otro lado, los operarios de fundiciones, estructura y cerramiento quedarían parados durante el invierno. Si se quiere que todo el mundo trabaje durante todo el año, debe poderse hacer todo en la época invernal.

\section{Trabajos de preparación para realizar estructuras y cerramiento en invierno}

A lo más tardar, en octubre debe decidirse si se realizarán las obras de estructura y cerramiento en invierno. Si se espera en esta decisión, hasta haber comenzado las inclemencias propias de la estación, entonces es tarde para hacer preparativos. En otoño deben de estar acabados los trabajos de movimientos de tierras, desagües, cimientos $\mathrm{y}$, si es posible, los muros de los sótanos; además, las tuberías de agua deben estar protegidas contra las heladas. Antes de empezar el invierno es conveniente disponer los accesos y comunicaciones en la propia obra. Es igualmente importante preparar de antemano el drenaje general.

\section{Obra en invierno al aire libre}

En las obras al aire libre se deben proteger las partes sensibles a la humedad, nieve y heladas, es decir, los materiales almacenados, la maquinaria, el hormigón fresco y la fábrica de ladrillo recién construida. El resto de la obra puede quedar sometido a la intemperie.

En estos casos es muy necesario disponer de alojamientos con calefacción para todos los operarios, con posibilidad de lavarse, secar la ropa y calentar la comida.

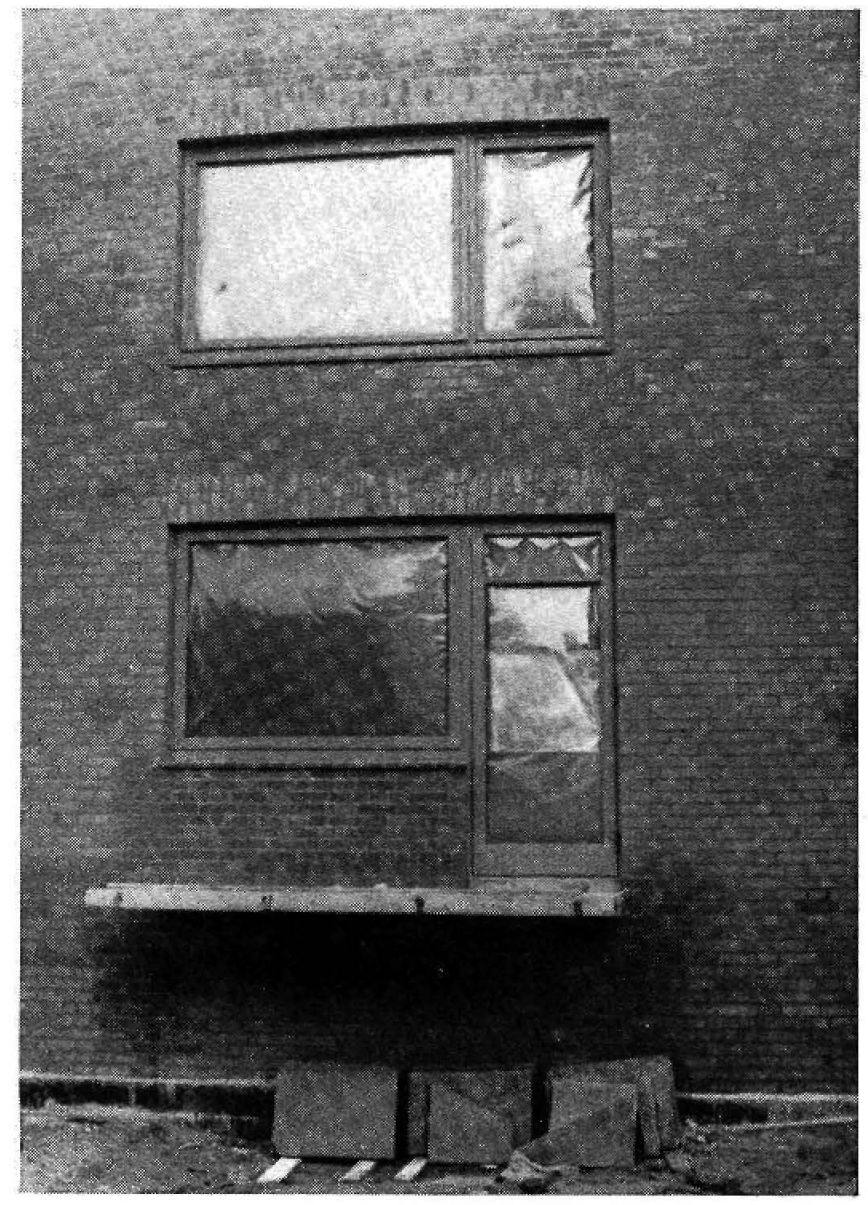

Fig. 1,-Ventanas y puertas de balcones cerradas con hoja de plástico para la realización de la obra en invierno. 
Los materiales se reservan en sitios protegidos y secos, y se cubren con lonas o telas plásticas (fig. 2). Las máquinas mezcladoras se disponen bajo una cubierta o bajo una carcasa protectora (figura 3). Es necesaria una instalación para la alimentación continua de agua caliente, tanto para preparar el mortero como el hormigón (fig. 4). Antes de realizar los forjados de hormigón se debe calentar el encofrado desde abajo, lo que se puede conseguir cerrando las ventanas de la planta inferior y colocando estufas en ella. El hormigón se confecciona con agua caliente; si es necesario, se calientan también los áridos. El hormigón fresco se protege con lonas o con esteras de paja (figuras 5 y 6 ). La fábrica de ladrillo se debe levantar con mortero caliente $y$, si es necesario, con ladrillos calientes, cubriendo todo ello como en el caso del hormigón (figura 7). Todos los lugares fijos de trabajo (montacargas, hormigoneras, etc.) se deben proteger del viento y la lluvia. Existen también ligeras cubiertas protectoras móviles para preservar el trabajo en los muros (figura 8).

Con estas medidas se ha trabajado los últimos seis inviernos, con un número normal de operarios, hasta 5 grados bajo cero.

Fig. 2.-Montones de materiales apilaFig. 2,-Montones de materiales apila-
dos cuidadosamente y cubiertos de plás. tico.

Fig. 3.-Instalación de mezela en una obra de invierno con careasa protectora.

Fig. 4.-Instalación para la obtención de vapor y agua caliente de la obra en invierno.
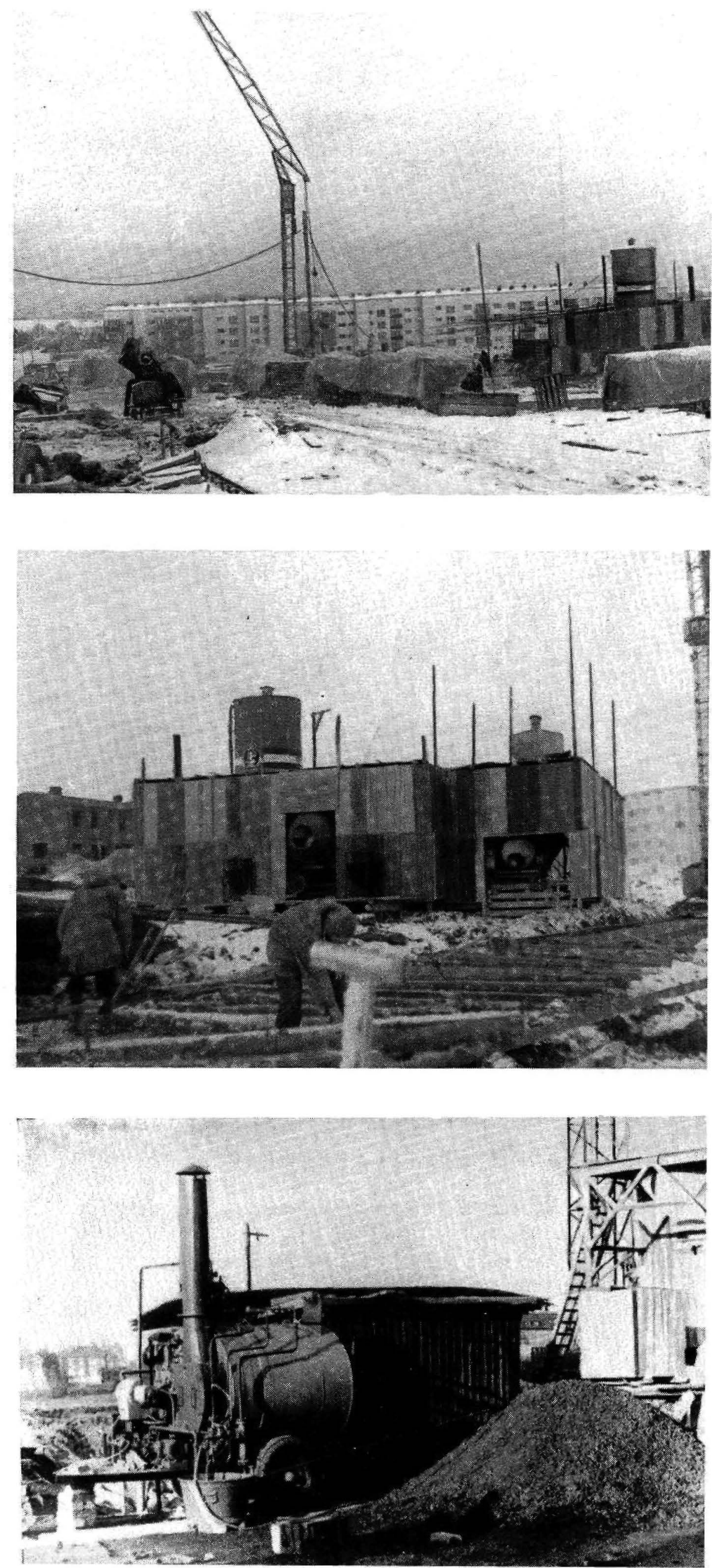


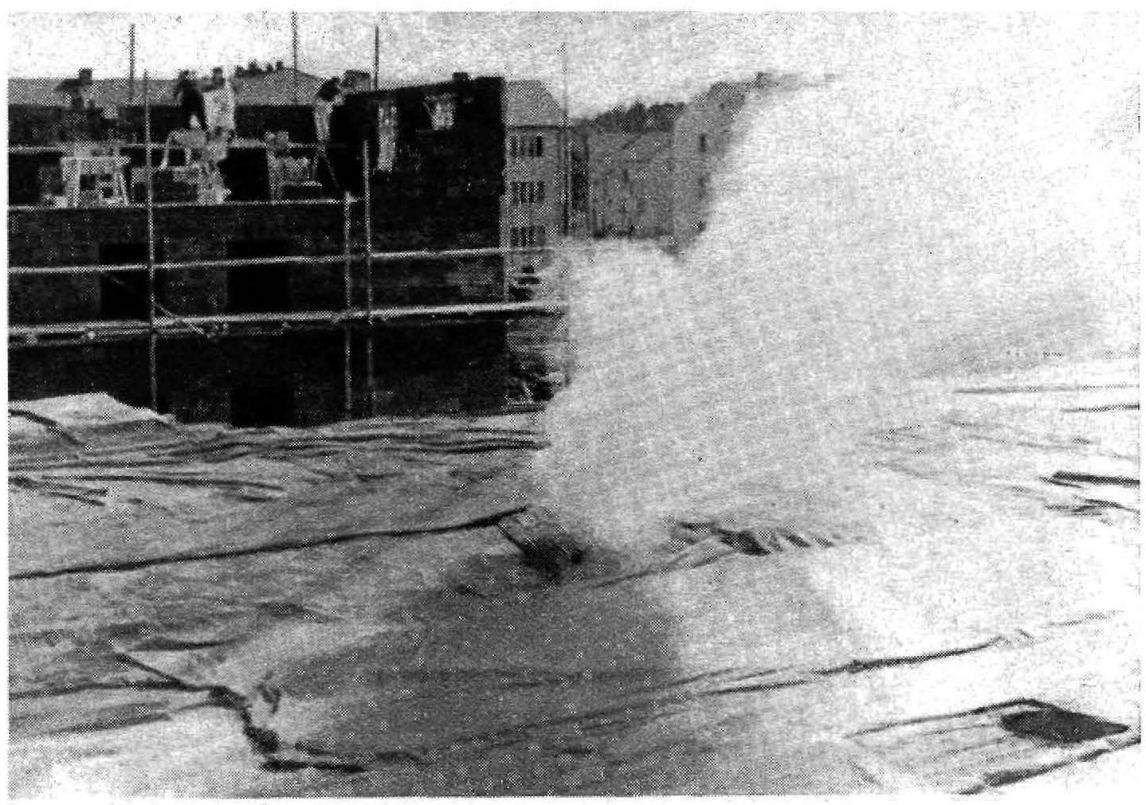

Fig. 5.-Forjado reeién hormigonado cuFrjado recien hormigonado

Fig. 6.-Cubrición y calefacción en un forjado de hormigón freseo armado.

Fig. 7.-Fábrica de ladrillo reciente protegida contra los daños de las heladas por medio de mantas.

Después de terminar los trabajos preliminares necesarios se comenzó la consirucción de 64 viviendas el 1 de noviembre. Los trabajos de estructura y cerramiento se acabaron el 1 de abril. A continuación tuvieron lugar los trabajos interiores (hasta fines de julio).

Los gastos adicionales de todas estas medidas especiales para poder trabajar en invierno, se dividen en tres grupos principales.

1. Gastos de adquisición y conservación de elementos auxiliares (estufas, lonas, etc.) e inversión de tiempo para montar y desmontar estos elementos. Estos son gastos fijos. Pueden representar un 25 por 100 del gasto adicional para la construcción en invierno.

2. Gastos para combustible, agua caliente, etc. La cuantía depende, naturalmente, de las condiciones atmosféricas y pueden representar hasta un 30 por 100 del gasto adicional.

3. Salarios y trabajos adicionales (movimiento de lonas, servicio de estufas, retirada de nieve, etc.). Estos trabajos dependen, igualmente, de las condiciones atmosféricas y pueden equivaler al 45 por 100 del gasto adicional de la construcción en invierno.

No es fácil determinar la cuantía de todos estos gastos en relación con el coste de la construcción. Esto depende de la época en que se realicen y de la inclemencia del tiempo. A continuación citamos un ejemplo que nos puede servir como referencia:

Fig. 8.-Armadura de protección de del Jugar de trabajo en la obra.

Durante el tiempo de construcción aparecieron un día de helada en noviembre, dos en diciembre, cinco en enero, dos en febrero y uno en marzo.

La inversión adicional exigida por la construcción en invierno representó, considerando todas las normas, un 3 por 100 del gasto del edificio, lo que representa un 7 por 100 a la obra de estructura y encofrados o un 10 por 100 en los elementos constructivos hechos en invierno.

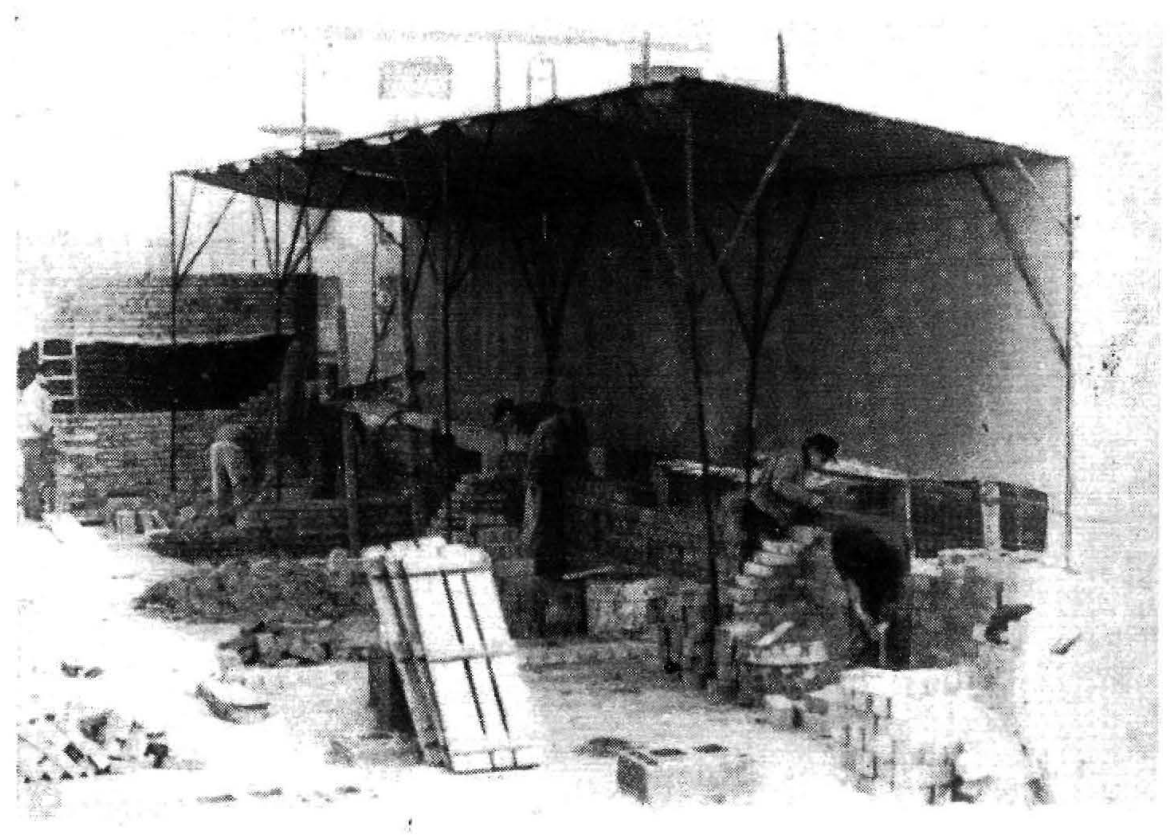

En una obra similar comenzada en enero, en la que no se emplearon todas las medidas de protección, se invirtió un 2 por 100 de gastos adicionales, 4 por 100 referido a la obra fundamental y 7,5 por 100 de los gastos para los elementos construidos en invierno.

La obra a la intemperie en esta época del año, presenta también la desventaja de que hay partes de la misma entre los montones protegidos de material, maquinaria y efectos de trabajo sometidas a los efectos de la intemperie. Nos referimos a los operarios que no trabajan en lugares fijos y protegidos. Los andamios y los accesos, por otra parte, pueden estar cubiertos por nieve o heladas.

En resumen: sería interesante cubrir toda la obra con una sola cubierta. Todos conocemos este tipo de construcciones en obras importantes, pero también sabemos que esta medida de protección resulta todavía costosa para la construcción de viviendas.

\section{Obra en invierno cubierta parcialmente}

Se ha intentado aprovechar las ventajas de una obra cubierta con una reducida inversión, cubriendo parte de la obra y dejando el resto sin protección.

En una obra de tipo experimental del Ministerio Federal de la Vivienda para la construcción de viviendas en el Berlín Oeste, se tenía que realizar durante el invierno 1960-1961 la obra de estructura y cerramiento de un grupo de 61 viviendas. Para un grupo de 16 viviendas, la empresa constructora dispuso una carcasa protectora a base de tubos metálicos (figuras 9 y 10); en los costados se habían previsto hojas o láminas de plástico. Esta carcasa protectora ofrecía, además, espacio para la mezcladora. almacén de materiales y equipo de obra.

Mientras que las condiciones atmosféricas eran favorables, trabajó un grupo de obreros en la zona de 45 viviendas que estaban fuera de la carcasa. Al aparecer tiempo desfavorable se protegió la obra ya hecha 
El grupo de trabajadores trasladaron sus actividades a la zona de 16 viviendas situadas en el interior de la carcasa (figs. 11 y 12). Durante el invierno 1960-1961, que fue relativamente favorable, se construyó, además de las 16 viviendas en el interior, la estructura y cerramiento de las 45 que están a la intemperie.

Los gastos para montaje y desmontaje de la carcasa protectora resultan ser de 21.000 DM. Estos fueron los gastos fijos. Para las medidas auxiliares dependientes del tiempo (calefacción, cubrición de elementos exteriores, etc.) se invirtieron, además, 6.000 DM. Con esto, hay que añadir, al gasto del edificio de las 16 viviendas hechas bajo cubierta, un 16 por 100 más como medidas adicionales para el invierno, lo que representa un 30 por 100 de los gastos de la obra básica o un 45 por 100 de los trabajos realizados bajo cubierta.

$\mathrm{Si}$ relacionamos la inversión adicional a todas las viviendas (en un total de 61) que se realizaron con estas medidas en e] invierno, entonces obtenemos menos de un 3 por 100 de aumento de inversión.

Esta disposición de la obra en el invierno hizo necesario el desplazamiento del lugar de trabajo de los grupos de obreros según las condiciones atmosféricas reinantes. Esto es, en general, desfavorable en relación con el desarrollo de los trabajos y los rendimientos.

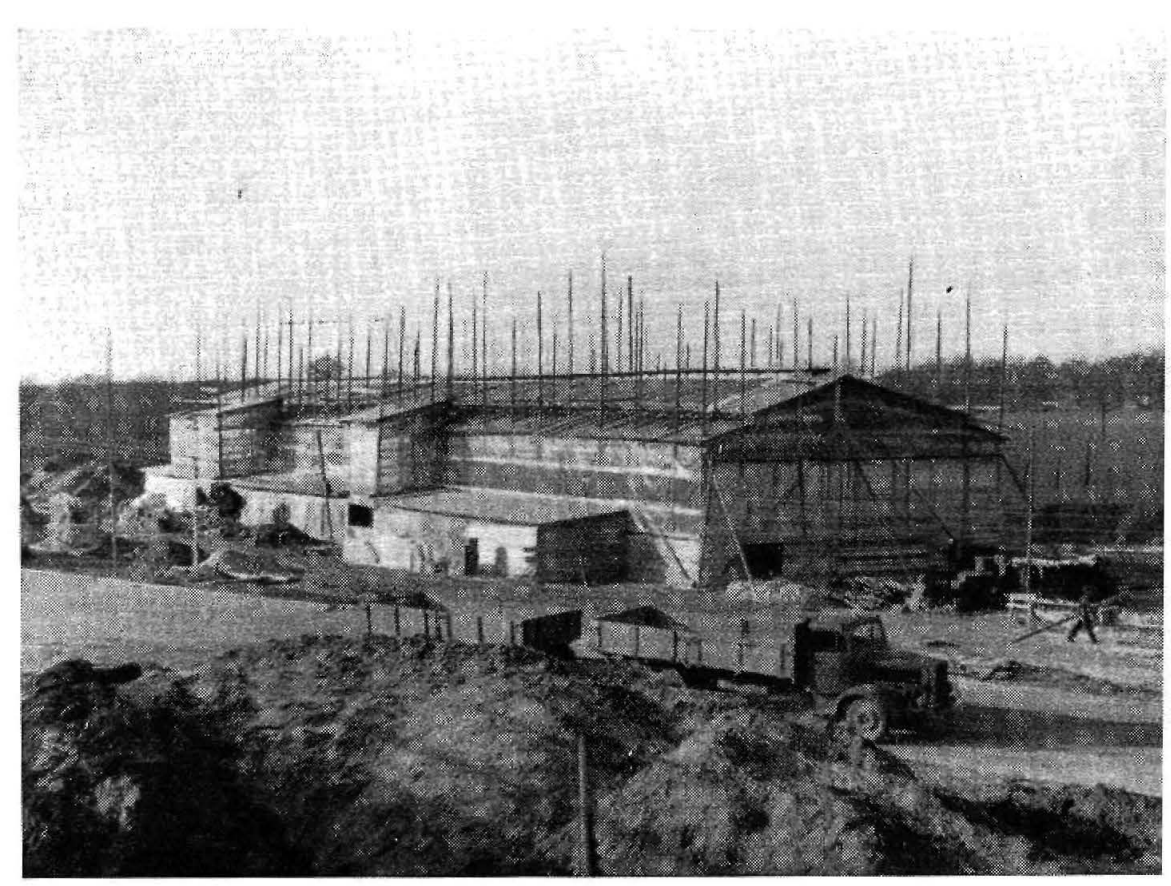

Fig. 9.-Careasa protectora suspendida por armadura de tubos y cerrada con folios de plástico.

\section{Obra cerrada en invierno}

Consecuencia de lo anterior, parece más adecuado buscar medios que permitan proteger el total de la obra frente a las inclemencias del tiempo.

Esto sería posible si cubriéramos la obra con una tienda de campaña, pero esta tienda debería ser lo suficiente para cubrir también los accesos, los almacenes de materiales y la maquinaria. En estas condicio-

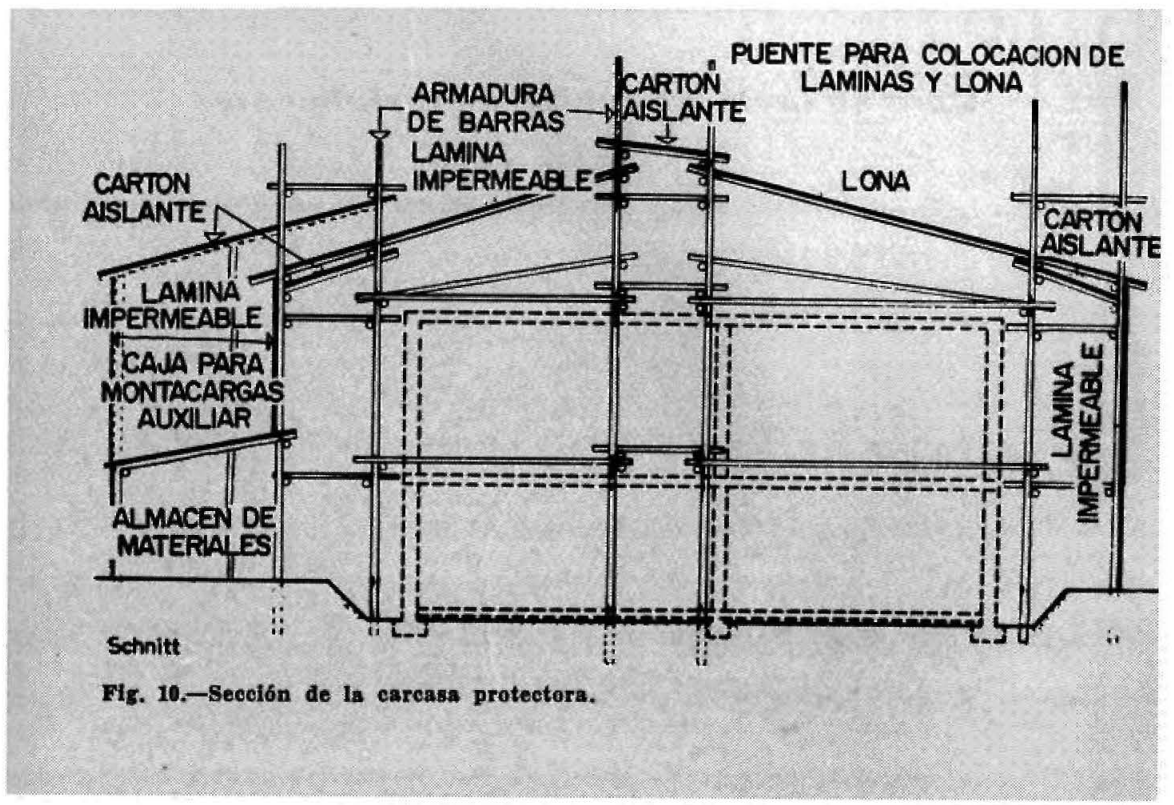


Fig. 11.-Obra y armadura en el interior de la carcasa protectora de las figuras 9 y 10 .

Fig. 12.-Montacargas, armadura y forjado de hormigón en el interior de la carcasa protectora.

nes podría colocarse calefacción e iluminación, obteniendo, en consecuencia, unas condiciones atmosféricas de verano.

Una tienda de este tipo se puede levantar con una altura limitada. Si se quiere emplear para edificios altos, el montaje en altura y el arriostramiento frente a los efectos de viento originarían gastos elevados y medidas constructivas caras. Por estos motivos no se emplea una armadura de protección para edificios altos en toda su altura. Es más lógico montar a nivel de tierra una armadura y elevarla en conjunto a medida que crece el edificio. Bajo estas condiciones no precisaría la armadura una estabilidad propia, ya que la obtendría por fijación a la parte de obra terminada.

Un dispositivo de este tipo ha sido desarrollado por una empresa constructora de viviendas, habiéndolo empleado con éxito durante varios años. La cubierta de la casa se montó a ras de tierra, elevándola a medida que subían los muros.

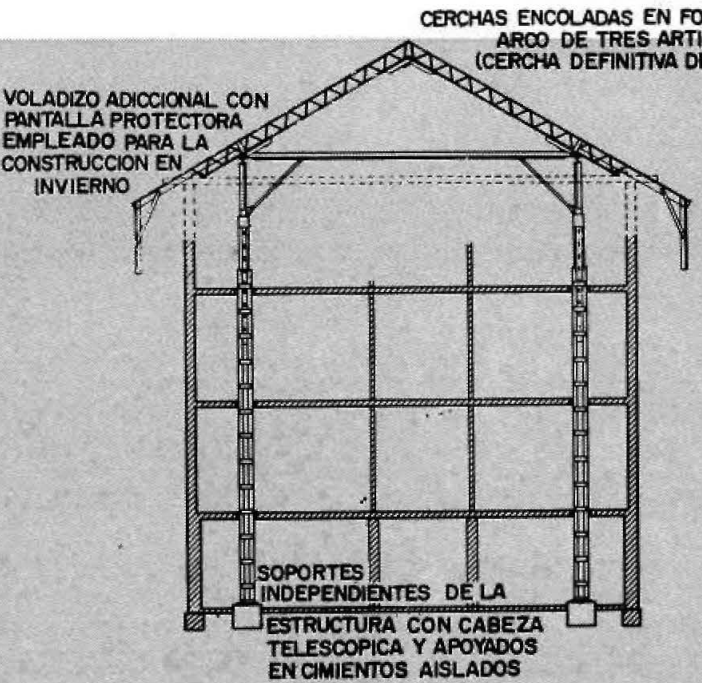

Fig. 13. - Cubierta con elevación para la construcción de casas altas en invierno (*Cludad Libres, de Hamburgo).
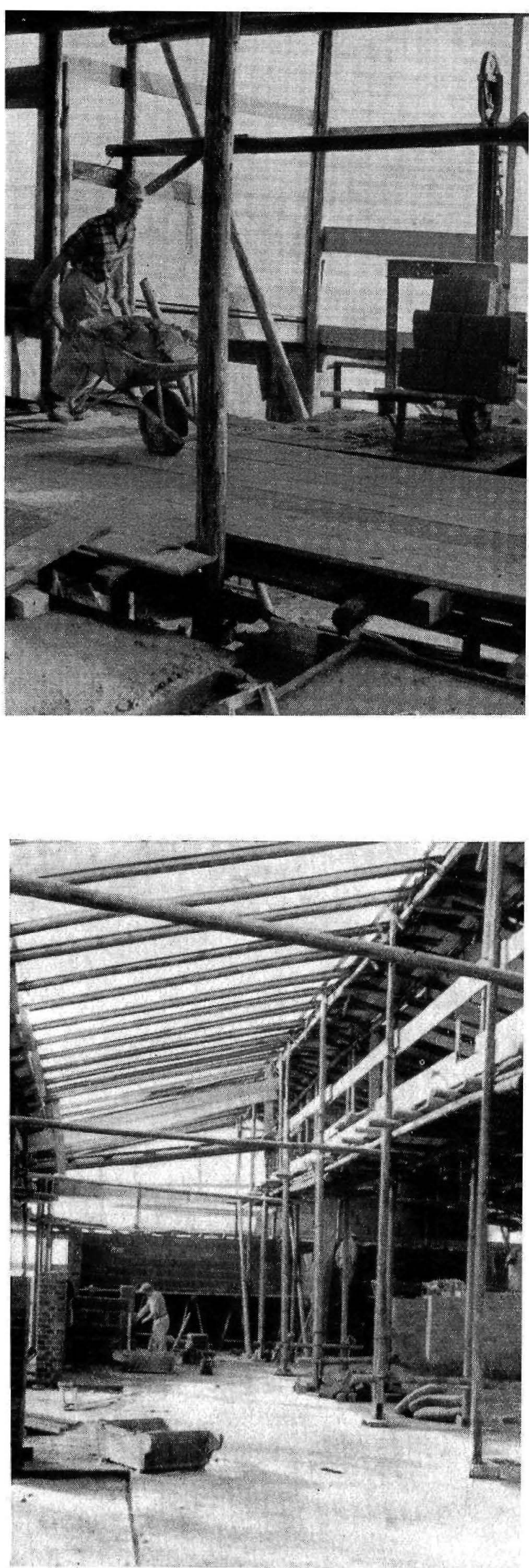

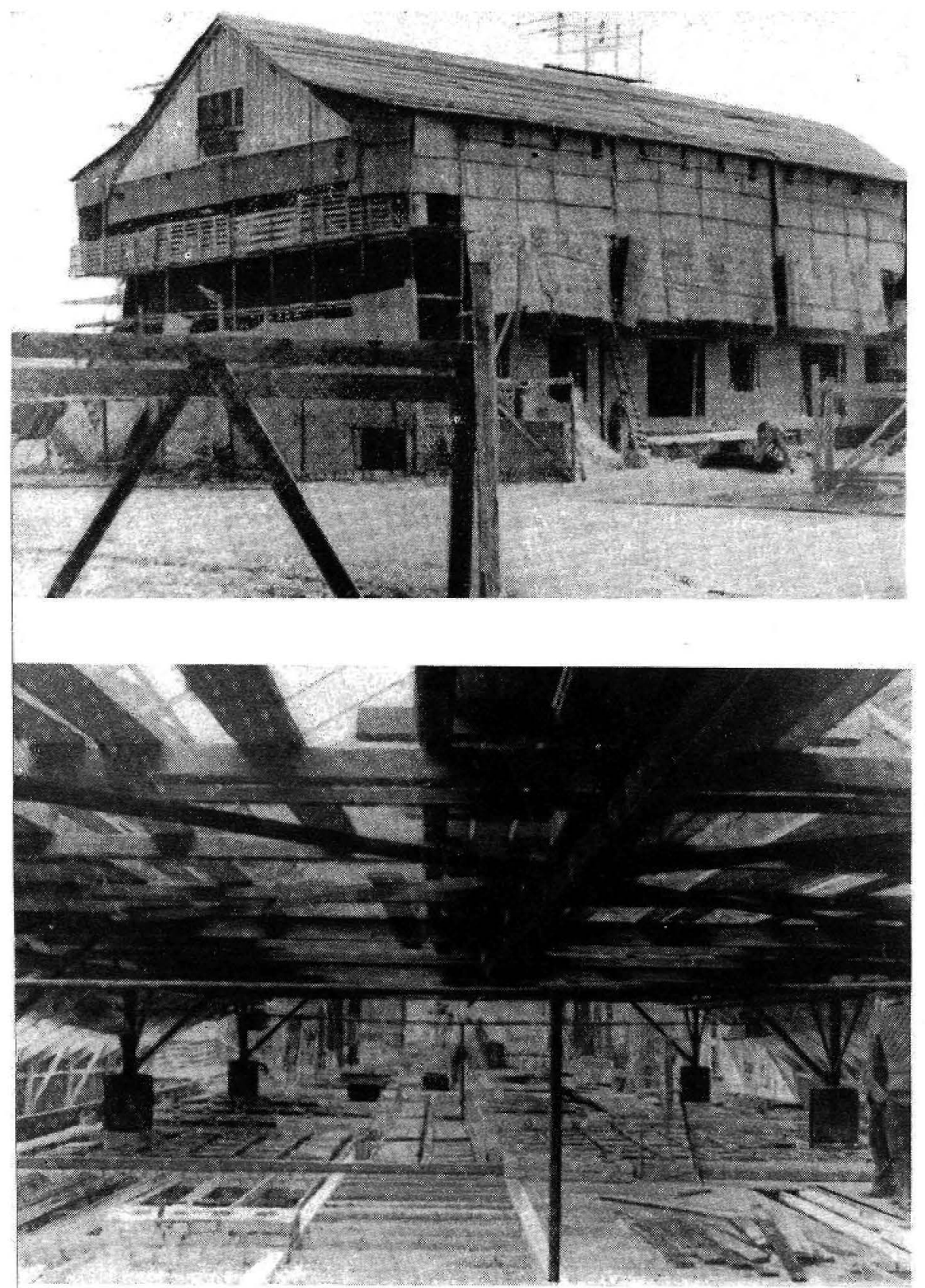

Fig. 14.-Obra gruesa bajo la cubierta con elevación de la flgura 13.

Fig. 15. - Construcción de un forjado de hormigón armado debajo de la cubierta protectora de las figuras 13 y 14 .

Esta cubierta tiene voladizo de $1,5 \mathrm{~m}$. Así se resguarda el edificio, y las esteras o paramentos laterales protegen los costados de las plantas donde se realizan trabajos (figuras 13 y 14). Los almacenes de material y las instalaciones de mezcla deben disponerse en proximidades del edificio, cubriendo estos lugares con lonas o tiendas de campaña. Con esta ordenación se realizaron la mayoría de los trabajos bajo la cubierta y protegidos por los paramentos. La zona de trabajo conseguida de esta forma se puede calentar e iluminar (figura 15).

Construcciones similares se han realizado va hace tiempo en Austria, con la denominación de «naves para construcción en invierno» (figura 16).

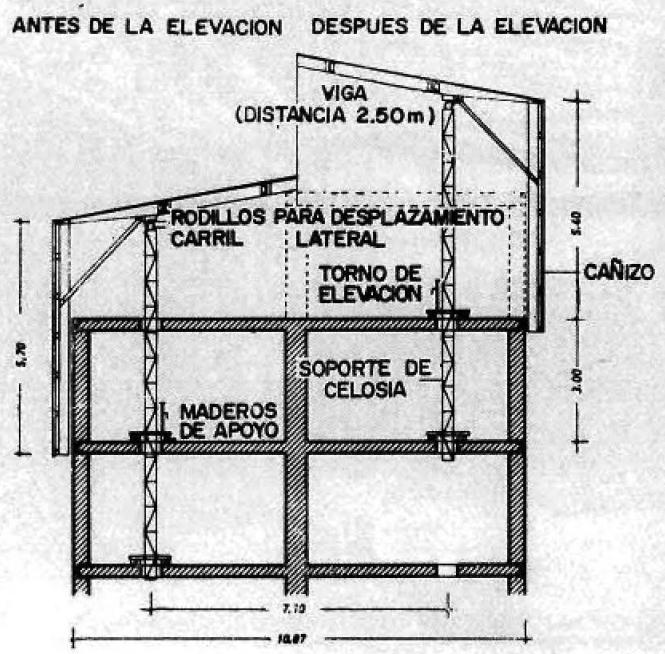

Fig. 16.-Nave para la construceión en invierno em. pleada en Viena.

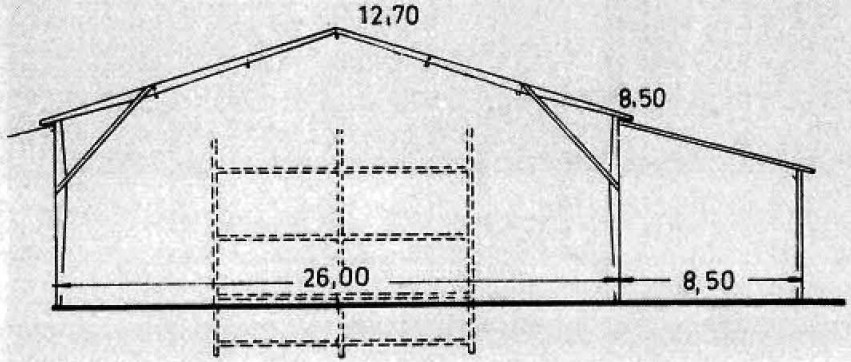

Fig. 17.-Tienda de eampaña amplia y de fácil montaje y desmontaje, apropiada tambiên como nave para construcción en invierno. 
Los gastos para este tipo de instalaciones resultan considerables en la realidad. En la construcción de Hamburgo se tiene que considerar un gasto de 40.000 a $60.000 \mathrm{DM}$, según la amplitud del edificio, para los trabajos de montaje y desmontaje, desplazamientos de la cubierta, calefacción e iluminación, alojamiento de los operarios, y otras medidas necesarias en la construcción de invierno, que representa, en consecuencia, un 8 a 11 por 100 del coste del edificio. Bien es verdad que no se debe calcular siempre con estos gastos tan elevados. En Hamburgo se construyeron con este dispositivo edificios de cuatro plantas. $\mathrm{Si}$ estos edificios hubiesen sido de mayor altura se podía haber empleado la misma instalación y, por tanto, el porcentaje hubiese sido más reducido en relación con la envergadura de la obra. Para un edificio de ocho plantas, considerando las mismas condiciones adicionales para la construcción de invierno, se hubiese obtenido un equivalente del 5,5 al 7,5 por 100 .

Mucho más sencillas son las instalaciones de protección similares a las mencionadas, pero tratándose de edificios bajos. Los edificios de dos o tres plantas se pueden realizar en una misma tienda de campaña con una altura máxima de 13 metros. En una tienda de este tipo-50 $\mathrm{m}$ de longitud y $26 \mathrm{~m}$ de ancho-con una nave previa en la longitud de $8,5 \mathrm{~m}$, se pueden construir, por ejemplo, 7 viviendas unifamiliares de dos plantas con un ancho de $6,5 \mathrm{~m}$. En caso de necesidad se puede disponer tres crujías a dos plantas con un ancho de $15 \mathrm{~m}$ (figuras 17 y 18).

En los trabajos preliminares de un edificio de ensayo realizado el pasado invierno se calcularon para el inontaje y desmontaje de la tienda de campaña 7.000 DM., para el alquiler 3.000 DM., y para los trabajos de invierno (calefacción, iluminación, etc.) también 3.000 DM. Por este valor de 13.000 DM. se pudo crear una obra con unas condiciones equivalentes a las del verano, realizándose los trabajos sin perturbaciones.

Los gastos del edificio de las 7 viviendas unifamiliares-cada una de 40.000 DM.-se recargaron con el 5 por 100. A los gastos de edificio de las viviendas relativamente más pequeñas con dos crujías y tres plantas-cada una de un valor de 25.000 DM.-, los gastos adicionales hubieran resultado de un 3,3 por 100 para la tienda de campaña y las medidas especiales de invierno.

Las naves de la casa Krupp, de Essen, citadas múltiples veces en el presente año, están soportadas por aire y proporcionan condiciones de traba o similares a la tienda de campaña. 


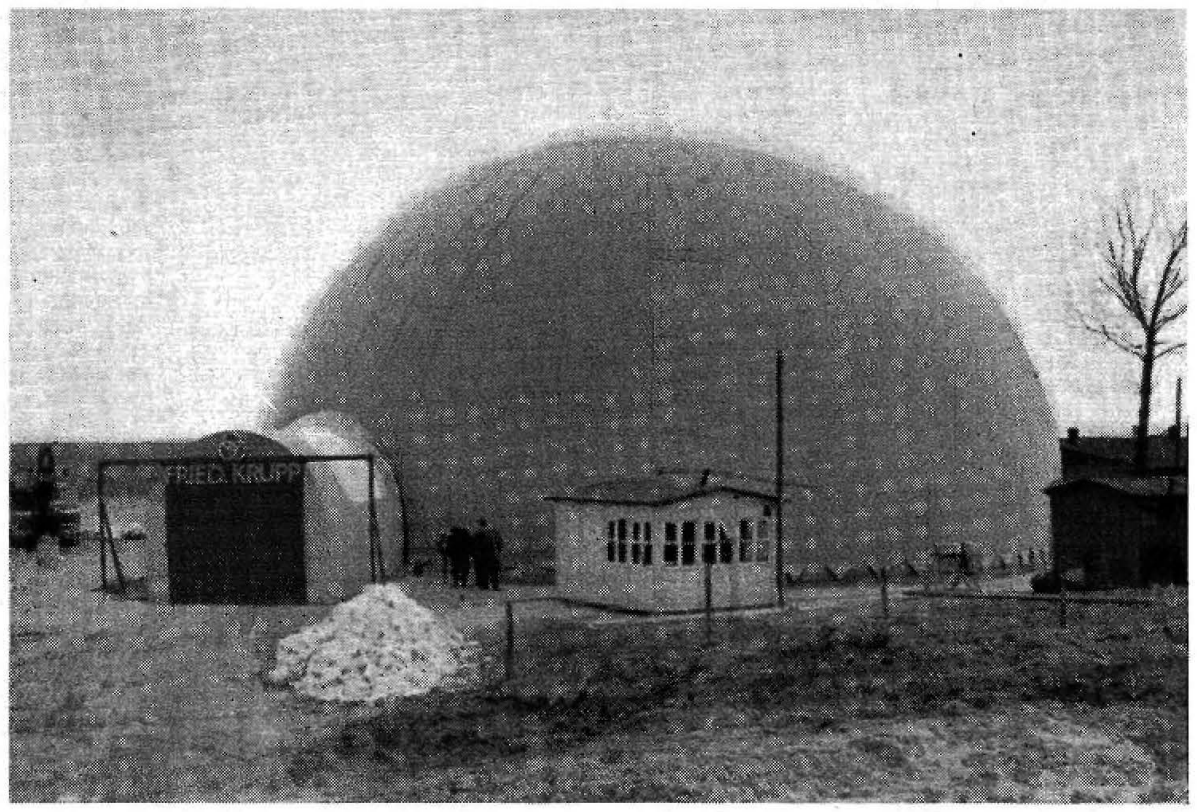

Fig. 19.-Nave soportada por aire de la casa Friedrich Krupp.

No se debe dejar sin considerar que los edificios que se construyen en el interior de estas naves no se pueden levantar en el centro en su mayor altura, sino en un lateral. Con una profundidad de $26 \mathrm{~m}$, se precisa una zona necesaria como acceso y para almacenamiento de materiales, aparatos y alojamiento (figuras 19 y 20).

\section{Conclusiones}

Las dificultades que se presentaban en la construcción continua en invierno parecían tan amplias hace algunos años, que se llegó a pensar seriamente si había de prescindirse de la construcción en esta época del año, pero las experiencias más recientes han demostrado que se pueden solventar las dificultades técnicas. En el futuro se tendrán que crear también en el invierno en la obra, condiciones de trabajo con las cuales se puedan seguir los trabajos. Las condiciones más favorables son las de la obra cerrada.

Las inversiones adicionales que hay que tener en cuenta al continuar los trabajos en el invierno sin originarse perjuicios técnicos en los edificios son, en realidad, bastante elevadas. Estas medidas se deben considerar cuidadosamente según el tipo de edificio, con el fin de delimitar, al máximo, los gastos adicionales que son innecesarios. Las ventajas surgidas frente a estos gastos adicionales no se deben buscar sólo en el hecho en sí de construir en el invierno. Si con estas inversiones adicionales se consigue una actividad continua en la construcción durante todo el año, las ventajas se reflejan en una capacidad superior en la economía de la construcción; esto trasciende en

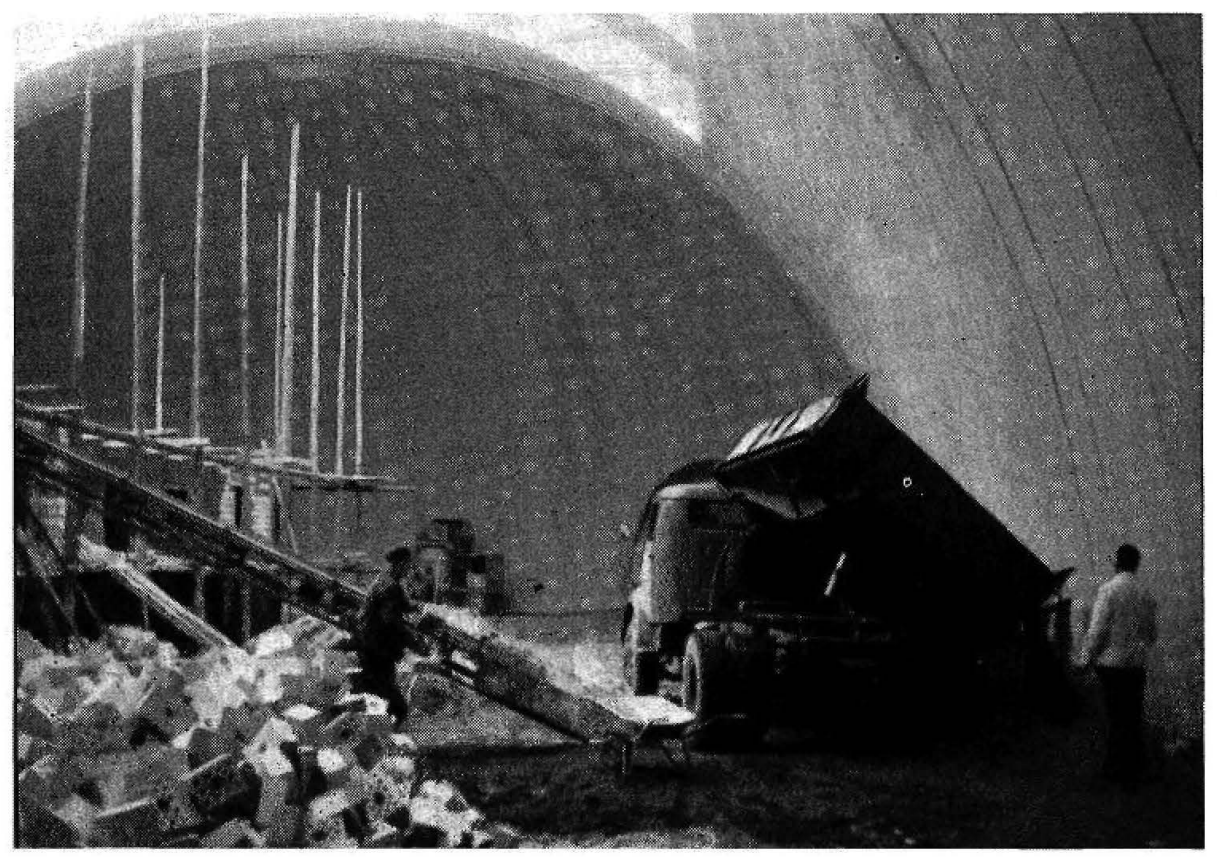
una construcción más económica, que no solamente es para el bien de todos los que colaboran en ella, sino que en muchos casos han proporcionado ventajas inmediatas para los constructores e, igualmente, para los propietarios.

Fig. 20.-Realización de los trabajos en el interior de la nave soportada por aire de la figura 19. 